\title{
A 'CRISE HÍDRICA' NA REGIÃO METROPOLITANA DE SÃO PAULO: ANÁLISE DA VARIABILIDADE PLUVIAL E A REPERCUSSÃO HÍDRICA NO SISTEMA CANTAREIRA
}

\author{
Pedro Augusto Breda Fontão ${ }^{1}$ \\ João Afonso Zavattini
}

Resumo: Trata-se de uma investigação que buscou a compreensão da variabilidade pluvial na Região Metropolitana de São Paulo (RMSP) e seus reflexos no armazenamento hídrico do Sistema Cantareira, principal manancial de abastecimento da metrópole, dando ênfase para o episódio da crise hídrica sucedida entre os anos 2014-2015. A RMSP está inserida na porção leste do estado de São Paulo, destacando-se por ser o maior e mais populoso aglomerado urbano do território brasileiro, e notoriamente encontra-se sujeita a eventos extremos. Nesta região, selecionaram-se postos pluviométricos representativos no sentido nordestesudoeste e avaliou-se as chuvas em nível mensal pelo método Boxplot e, a partir dos parâmetros habituais apreciados, analisou-se a distribuição das chuvas na região associada às variações do volume armazenado e captado no Sistema Cantareira, para fins de planejamento urbano e ambiental.

Palavras-chave: Recursos Hídricos; Chuva; Seca; Abastecimento Urbano; Climatologia.

\section{THE 'WATER CRISIS' IN THE METROPOLITAN REGION OF SÃO PAULO: ANALYSIS OF RAINFALL VARIABILITY AND HYDRIC IMPLICATIONS IN THE CANTAREIRA SYSTEM}

Abstract: This is a research that sought to understand the rainfall variability in the Metropolitan Region of São Paulo (SPMR) and its effects on the water storage of the Cantareira System, main source of water supply of the metropolis, emphasizing the episode of the water crisis happened between the years 2014-2015. The SPMR is located in the eastern area of the state of São Paulo, and stands out as the largest and most populous urban agglomeration in the Brazilian territory, and is notoriously subject to extreme events. In this region, pluviometric stations were selected in the northeast-southwest direction and monthly rainfall was analyzed using the Boxplot method, and from the usual parameters adopted, rainfall distribution was analyzed in the region associated with variations in water stored and used in the Cantareira System, for urban and environmental planning purposes.

Keywords: Water resources; Rain; Drought; Urban Supply; Climatology.

\footnotetext{
${ }^{1}$ Doutor em Geografia pela Universidade Estadual Paulista (UNESP) - Campus de Rio Claro e Professor Adjunto no Departamento de Geografia da Universidade Federal do Paraná (UFPR). pedrofontao@ yahoo.com.br

${ }^{2}$ Docente do Departamento de Geografia da Universidade Estadual Paulista (UNESP) - Rio Claro. zavattini@ @c.unesp.br
}

Estudos Geográficos, Rio Claro, 17(1): 43-54, jan./jun. $2019 \quad$ (ISSN 1678-698X) 
A 'crise hídrica'...

\section{INTRODUÇÃO}

A compreensão do fenômeno das precipitações tem se mostrado uma importante questão no âmbito da ciência geográfica, sobretudo em regiões intertropicais. Nessa perspectiva, a variabilidade das chuvas apresenta grande relevância nas escalas regional e local, principalmente devido à sua capacidade de afetar diretamente o ser humano e influir na organização do espaço. Isto posto, a despeito da dinâmica atmosférica exprimir circunstâncias habitualmente esperadas na maior parte do tempo, tais irregularidades temporais e espaciais, inerentes à variabilidade pluvial, podem provocar situações atípicas e sequências de tipos de tempo excepcionais no qual a população de um determinado local nem sempre se encontra preparada.

Diante disso, apesar de episódios e eventos extremos serem possíveis de ocorrer em qualquer região do planeta, as áreas densamente povoadas tendem a apresentar maior repercussão desses incidentes, como é o caso das grandes metrópoles. No Brasil, a Região Metropolitana de São Paulo (RMSP) distingue-se por ser o maior e mais populoso aglomerado urbano do país, e notoriamente estar sujeita a eventos extremos relacionados, por exemplo, a chuvas intensas (LIMA et al., 2010) e a grandes episódios de estiagem (COELHO et al., 2016).

Em um período recente, um assunto intimamente relacionado ao dinamismo atmosférico sobressaiu-se na RMSP e apresentou grande destaque e repercussão nos meios de comunicação brasileiros, através de um evento relacionado ao ritmo pluvial excepcional. Todavia, não se tratou de um fato relacionado a precipitações volumosas e/ou episódios de cheias e inundações que continuamente tem ganhado destaque por, infelizmente, desencadear impactos intensos e tragédias na metrópole e ao longo do centro-sul do país. No caso, tratou-se da escassez dos recursos hídricos entre os anos 2014-2015 desencadeada por um longo período de baixa precipitação no sudeste brasileiro, que ficou conhecido como "crise hídrica" (CUSTÓDIO, 2015; JACOBI et al., 2015, dentre diversos outros estudos).

À vista disso, a escassez hídrica motivada por um longo episódio de seca meteorológica teve seu auge na RMSP, no tocante à possibilidade real de esgotamento dos mananciais e sistemas produtores de água para o abastecimento urbano da metrópole, notadamente o principal deles - o Sistema Cantareira, fator que comprometeria o fornecimento de água na região. Tal sistema é responsável por produzir cerca de 33 mil litros de água por segundo, recurso suficiente para abastecer um número próximo da metade de toda a RMSP (SABESP, 2018), sendo este o mais importante manancial para esta finalidade. A Figura 1 ilustra por meio do mapa as regiões em destaque que, sobrepostas, possuem a extensão de 9.941,2 $\mathrm{Km}^{2}$.

$\mathrm{Na}$ figura, nota-se que a RMSP tem seus limites inseridos, quase na sua totalidade, dentro da bacia do Alto Tietê, um dos seis compartimentos da bacia hidrográfica do Tietê elencados nas unidades de gestão de recursos hídricos do estado de São Paulo (SIGRH, 2018), base das Unidades de Planejamento Hídrico (UPH) em nível nacional (ANA, 2018). Em virtude de a metrópole paulistana estar localizada numa região de cabeceira, possuir atualmente uma população superior a 20 milhões de habitantes e $99,5 \%$ dela estar localizado na bacia do Alto Tietê (FUSP, 2009), tal setor é considerado "uma das bacias com menor disponibilidade hídrica por habitante no Brasil" (WHATELY e DINIZ, 2009, p.17). Entretanto, o Sistema Cantareira insere-se ao norte dessa região e apresenta a maior parte de

Estudos Geográficos, Rio Claro, 17(1): 43-54, jan./jun. $2019 \quad$ (ISSN 1678-698X) 
sua extensão fora dos limiares metropolitanos e dos limites hidrográficos da bacia do Alto Tietê, já na bacia dos rios Piracicaba-Capivari-Jundiaí (PCJ).

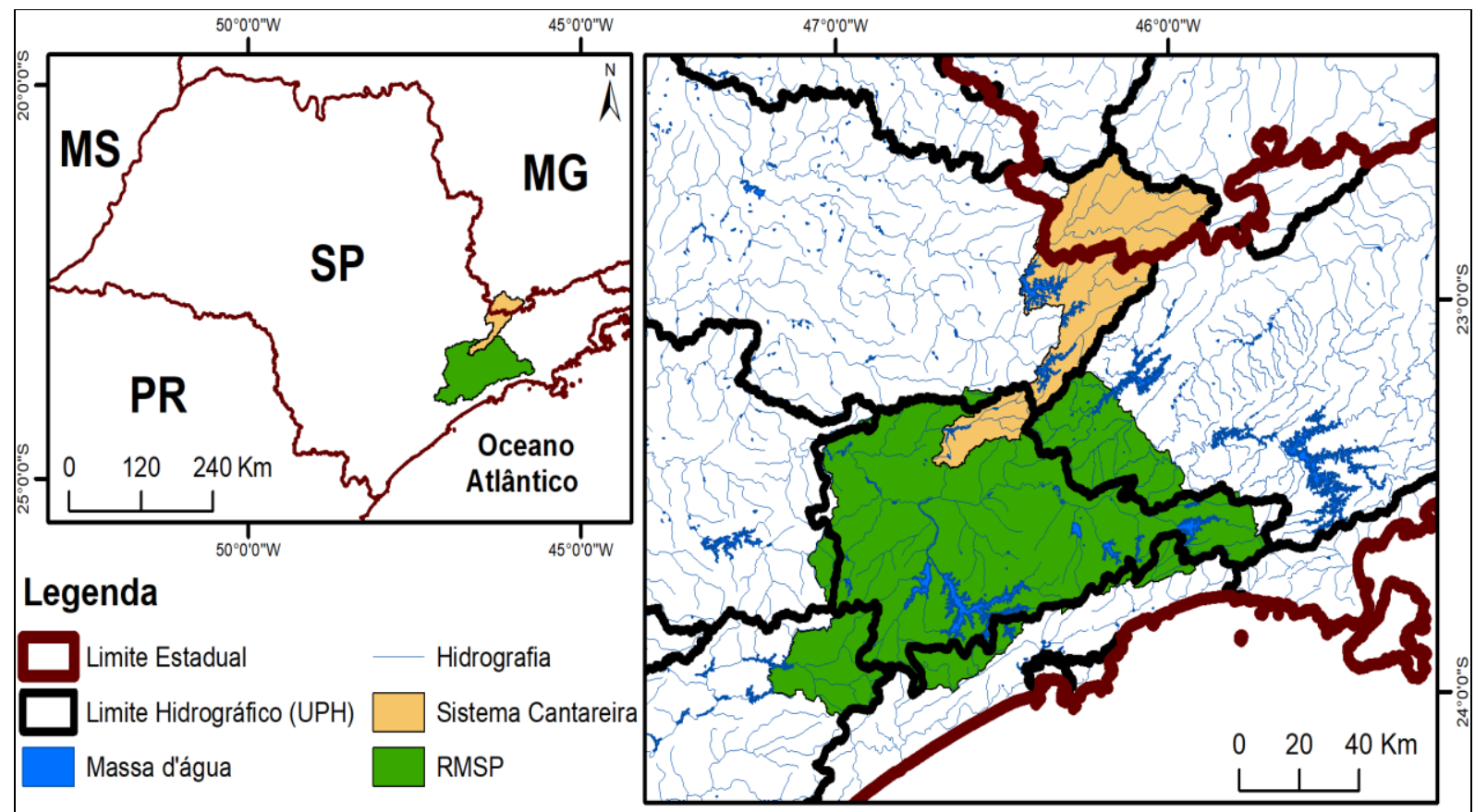

Figura 1 - Localização da RMSP, do Sistema Cantareira e dos limites hidrográficos.

Fonte: ANA (2018); SABESP (2018); SIGRH (2018).

Desse modo, para suprir as demandas de abastecimento na região metropolitana, os municípios dependem da importação das águas de outras regiões. Nesse ponto de vista, Ross (2008, p. 346) avalia que as águas de superfície dos rios Tietê e seus tributários de alto curso "são totalmente poluídas (...) A deficiência de água de boa qualidade e quantidade na alta bacia do Tietê obriga a importação de águas das altas bacias vizinhas". O Sistema Cantareira possui um total de seis reservatórios integrados no sentido nordeste-sudoeste através de túneis e regularizados em barragens, sendo cinco delas na região das nascentes da bacia do PCJ e um na bacia do Alto Tietê, transferindo as águas através de bombeamento em um desnível geográfico de cerca de 120 metros, pela estação elevatória de Santa Inês (SABESP, 2018).

Assim, a presente investigação empreendeu esforços no intuito de compreender e avaliar a variabilidade das chuvas ao longo do tempo (cronológico), tornando possível identificar o regime habitual das precipitações mensais através de postos representativos no espaço, numa perspectiva temporal-espacial. Da mesma maneira, analisou as repercussões pluviais durante o período da crise hídrica, visando determinar a intensidade da seca meteorológica. Outrossim, tendo em vista a relevância do Sistema Cantareira para o abastecimento urbano da RMSP, buscouse averiguar as variações nos volumes armazenados no sistema desde o último grande episódio de seca ocorrido em 2003 até o fim da crise hídrica de 2014-2015, associando tais variações às precipitações ocorridas, à produção hídrica do sistema e ao consumo de água na RMSP, no intuito de avaliar o episódio e gerar subsídios ao planejamento urbano e ambiental. 


\section{METODOLOGIA}

A área de estudo abrange toda a RMSP e o Sistema Cantareira, conforme já retratado anteriormente. Tendo como base a delimitação proposta, levantaram-se nas imediações os postos pluviométricos existentes e com registros consistentes de dados em série histórica através de elenco fornecido pela Agência Nacional de Águas (ANA) e pelo Departamento de Águas e Energia Elétrica (DAEE). No intuito de eleger postos representativos e com registros longos e contínuos de dados, selecionou-se quatro pluviômetros ordenados de forma quase linear no sentido nordeste-sudoeste desde o norte do Sistema Cantareira até a cidade de São PauloSP, sendo eles: Camanducaia (ANA), Joanópolis (DAEE), Nazaré Paulista (DAEE) e Observatório IAG (DAEE), ambos contemplando a série histórica de 1975 a 2015, ininterrupta. A Figura 2 exibe a distribuição geográfica de ambos.

Após tal procedimento de escolha, realizou-se a organização dos dados em nível mensal ao longo de toda a série histórica (1975-2015), na intenção de analisar e compreender a variabilidade das chuvas pelo gráfico Boxplot, instrumento que revela os quartis, a mediana e os valores extremos num conjunto de dados. Apesar de alguns pesquisadores defenderam a aplicação desse método estatístico para a identificação dos anos-padrão (SILVESTRE et al., 2013; SCHNEIDER e SILVA, 2014), esta etapa buscou somente estabelecer parâmetros válidos para avaliar os volumes habituais de chuvas na região, visando auxiliar numa análise mais detalhada das precipitações ocorridas durante a crise hídrica. Para a elaboração dos gráficos pelo modelo Boxplot, utilizou-se o software $R$ Project for Statistical Computing 3.5.
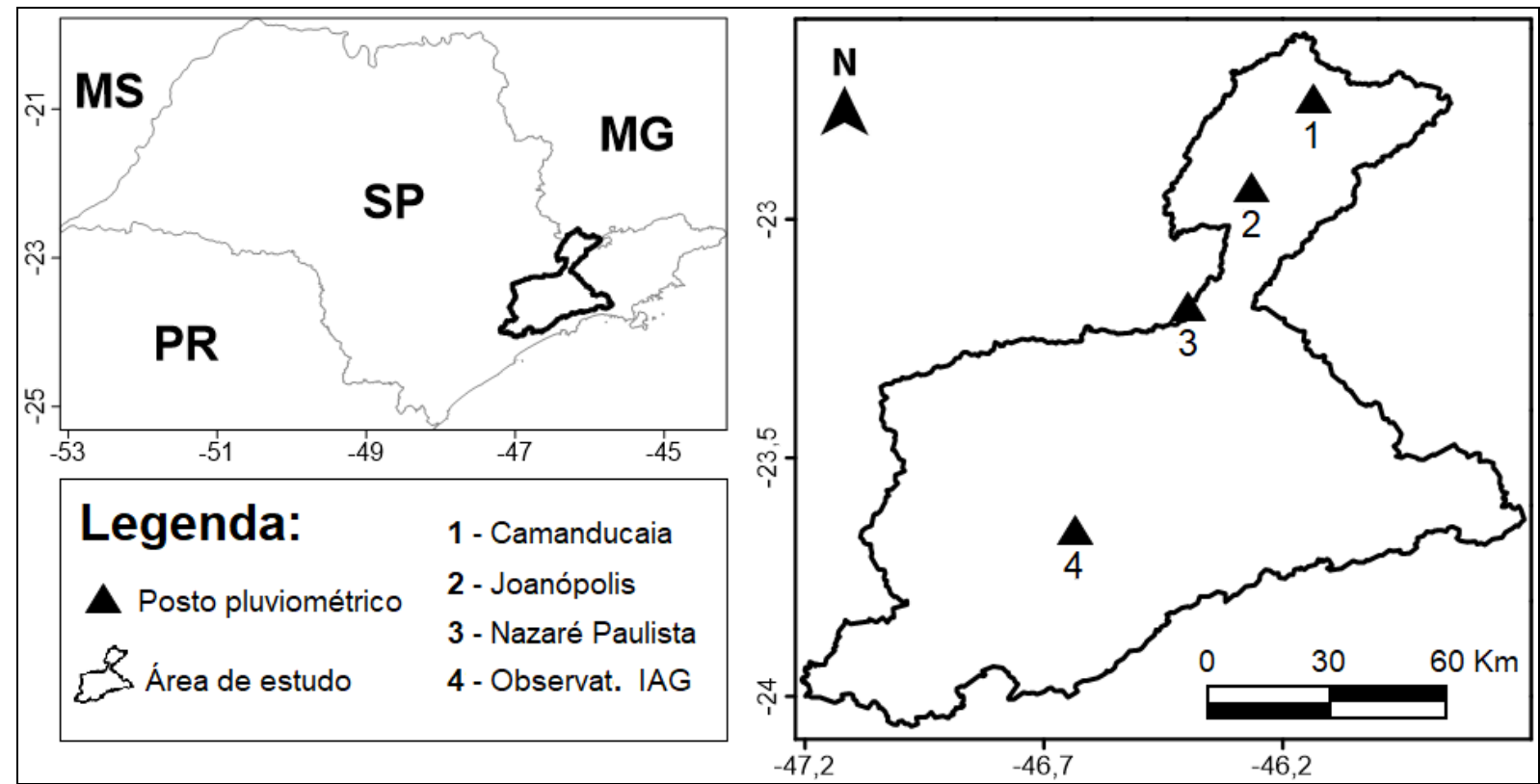

Figura 2 - Localização dos 4 postos representativos no sentido nordeste-sudoeste. Fonte: ANA (2018); DAEE (2018).

A partir do ano 2003, a Companhia de Saneamento Básico do Estado de São Paulo (SABESP, 2018), responsável por gerenciar e operar o Sistema Cantareira, passou a divulgar diariamente e de maneira detalhada o índice do volume hídrico armazenado no sistema. Desse modo, partindo do ano 2003 e tendo em vista a intrínseca relação entre o ritmo pluvial e o armazenamento hídrico, 
elaborou-se um gráfico-síntese com a distribuição contínua dos volumes mensais de chuva nos 4 postos e o volume hídrico armazenado no sistema, tornando possível uma análise mais detalhada sobre o tema. Para tanto, foi utilizado o software Microsoft Excel 2016.

Por fim, deve-se deixar claro que, apesar de existirem diversos outros elementos que podem influenciar nos processos de interceptação das chuvas, esta pesquisa optou por privilegiar de modo qualitativo o controle dominante da variável precipitação na recarga dos reservatórios inseridos nos limites hidrográficos do Sistema Cantareira. No entanto, procurando examinar de forma um pouco mais aprofundada o comportamento de outras variáveis importantes e avaliar os reflexos da crise hídrica nelas, obteve-se por meio da Sabesp (2018) os dados mensais da produção hídrica da companhia e de consumo doméstico de água na RMSP. Desta forma, elaborou-se um gráfico-síntese desses dados por meio do Excel, e uma análise posterior dos resultados obtidos auxiliado por publicações da época.

\section{RESULTADOS E DISCUSSÃO}

A princípio, foram gerados quatro gráficos Boxplot relativos aos postos selecionados nesse estudo, em uma longa série de dados (1975-2015). Tais figuras apresentam relevância para fins de análise comparativa e verificação dos totais mensais mais recorrentes (habituais) e os valores considerados extremos (excepcionais) para cada mês. Além disso, apresentam uma base e parâmetro para a análise mais aprofundada das precipitações compreendidas no período entre 2003 a 2015. Por isso, a Figura 3 apresenta os resultados de cada um dos postos no modelo Boxplot, e os respectivos quartis e valores extremos.

De maneira geral, nos quatro postos é possível notar um regime hídrico bem definido, mesmo considerando a variabilidade e/ou períodos extremos ocorridos nas séries, havendo uma concentração das chuvas nos trimestres janeiro-fevereiromarço e outubro-novembro-dezembro (primavera e verão austrais). Deste regime, típico das regiões tropicais do estado de São Paulo (SANT'ANNA NETO, 1995), nota-se uma redução da precipitação ao longo do mês de abril até o mês de setembro, intensificando-se a estiagem entre os meses de junho-julho e, principalmente, no mês de agosto. A grande presença de outliers, ou seja, valores extremos reforça a variabilidade característica das chuvas mensais em ambos os postos, com destaque para a existência de alguns meses que foram excepcionalmente chuvosos em relação ao habitual, apresentados pela distribuição dos dados. 


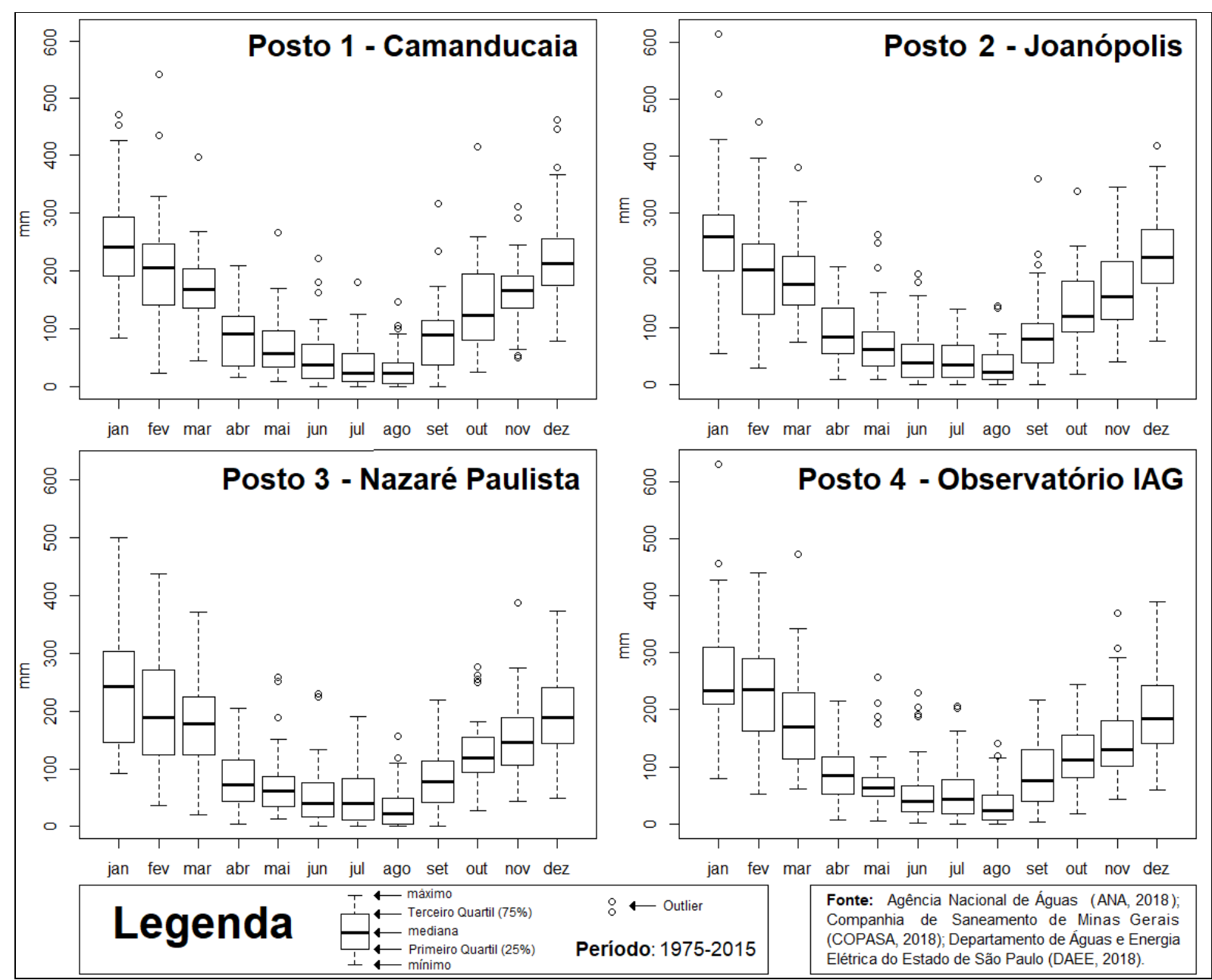

Figura 3 - Variabilidade mensal das chuvas pelo modelo Boxplot (1975-2015) nos 4 postos.

Fonte: ANA (2018); COPASA (2018); DAEE (2018).

A partir dos parâmetros observados nos gráficos Boxplot, avançou-se na pesquisa ao elaborar de maneira sintética gráficos de distribuição das chuvas em nível mensal ocorridas em sequência durante o período selecionado (2003-2015) nos quatro postos. Por tratar-se de uma análise vinculada ao principal manancial de abastecimento da metrópole, relacionou-se tais dados à variabilidade do volume armazenado no Sistema Cantareira, delineado segundo o volume útil total estipulado em 982 milhões de $\mathrm{m}^{3}$, além de incluir e indicar os dois momentos de incorporação do chamado "volume morto" (PORTO et al., 2014) por parte da Sabesp (2018), ocorrida nos dias 16 de maio e 24 de outubro de 2014, que englobavam a reserva técnica do manancial e adicionaram, respectivamente, 182,5 milhões de $\mathrm{m}^{3}$ e 105 milhões de $\mathrm{m}^{3}$ ao volume total do sistema. A Figura 4 permite visualizar as variáveis gráficas em questão.

Partindo da análise da figura, torna-se possível verificar a precipitação mensal ocorrida nos postos para toda a série (2003-2015), sobressaindo-se nesse intervalo volumes elevados de precipitação no Sistema Cantareira entre os anos de 2007 a 2011, dinamizado pelas chuvas excessivas ocorridas na primavera-verão destes anos. Todavia, entre 2012 e 2014, as chuvas mensais mostraram-se pouco substanciais ao longo de sua sazonalidade. Por consequência, os volumes armazenados no sistema acompanharam tal dinâmica de chuvas aquém do habitual em ambos os postos da área, sobretudo ao constatar que no ano 2010 a reserva 
hídrica havia atingido o índice máximo (100\% segundo a Sabesp, 2018) e, desde meados de 2011, passou a diminuir paulatinamente. Logo após 2012, apesar de alguns incrementos sazonais, o Cantareira apresentou queda expressiva nas suas reservas de água até o ano de 2014, tornando necessária a inclusão do "volume morto", reserva hídrica localizada abaixo da bomba de captação (SABESP, 2018).

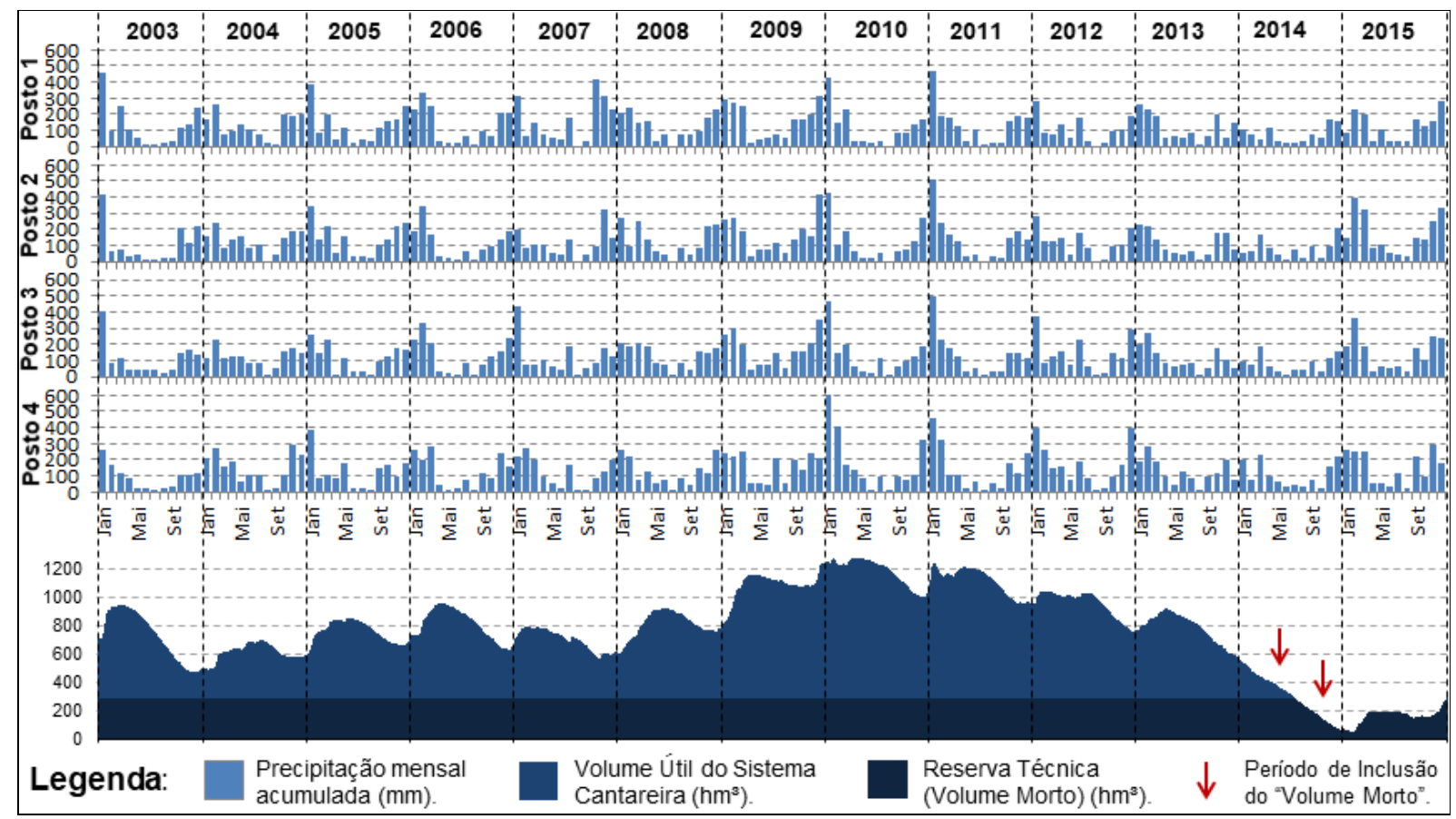

Figura 4 - Gráfico-síntese da precipitação e do volume no Sistema Cantareira (20032015).

Fonte: ANA (2018); DAEE (2018); SABESP (2018).

Ao verificar de modo comparativo as chuvas ocorridas em ambos os quatro postos, é possível notar alguns períodos de precipitação mais elevada na porção setentrional como é o caso, por exemplo, dos meses de outubro de 2007 a março de 2008 (primavera e verão). Em um sentido oposto, nota-se também situações onde ocorre tal desigualdade intrarregional, a título de exemplo a ocorrência de chuvas bem mais intensas na porção meridional no período de janeiro a março de 2010 e 2012. No caso do período de outono-inverno, apesar de algumas exceções (a exemplo de julho de 2009), as diferenças incitadas pela localização dos pluviômetros no total das chuvas mostraram-se pouco significativas, em virtude das parcas precipitações registradas habitualmente no semestre.

Isto posto, as precipitações reduzidas, quando ocorridas em meses de estiagem habitual (outono-inverno), não necessariamente caracterizaram um episódio de seca ou contribuíram de forma profunda para a queda abrupta dos reservatórios do Sistema Cantareira. Por outro lado, nas situações em que houve redução expressiva das chuvas nos trimestres de primavera e verão, notou-se uma contribuição significativa desses eventos para o déficit hídrico, a exemplo do ocorrido desde meados de 2003 até princípios de 2004 e, principalmente, durante a crise hídrica cuja seca meteorológica iniciou-se logo no inverno de 2013 e perdurou até o início de 2015. Ademais, no caso da crise hídrica, registraram-se volumes pluviais inferiores nos postos inseridos ao norte do Sistema Cantareira, justamente na área de recarga afluente dos reservatórios do sistema. 
Diante de tal quadro, solicitou-se à Sabesp (2018) os dados de produção total de água na RMSP, da produção hídrica exclusiva do Sistema Cantareira e o consumo doméstico de água na região metropolitana, ambos em nível mensal para toda a série avaliada (2003-2015). No caso da vazão de retirada do Cantareira, trata-se de limites pré-estabelecidos por outorga (DAEE, 2004), cuja variação sazonal é pequena e depende de um "banco de águas", ou seja, "permite o armazenamento do volume não utilizado no período de chuvas para uso em períodos de estiagem, ou seja, funciona como uma poupança para as regiões utilizarem em períodos mais críticos" (WHATELY e CUNHA, 2007, p. 14). A Figura 5 exibe na forma gráfica o resultado das três variáveis em questão ao longo do tempo.

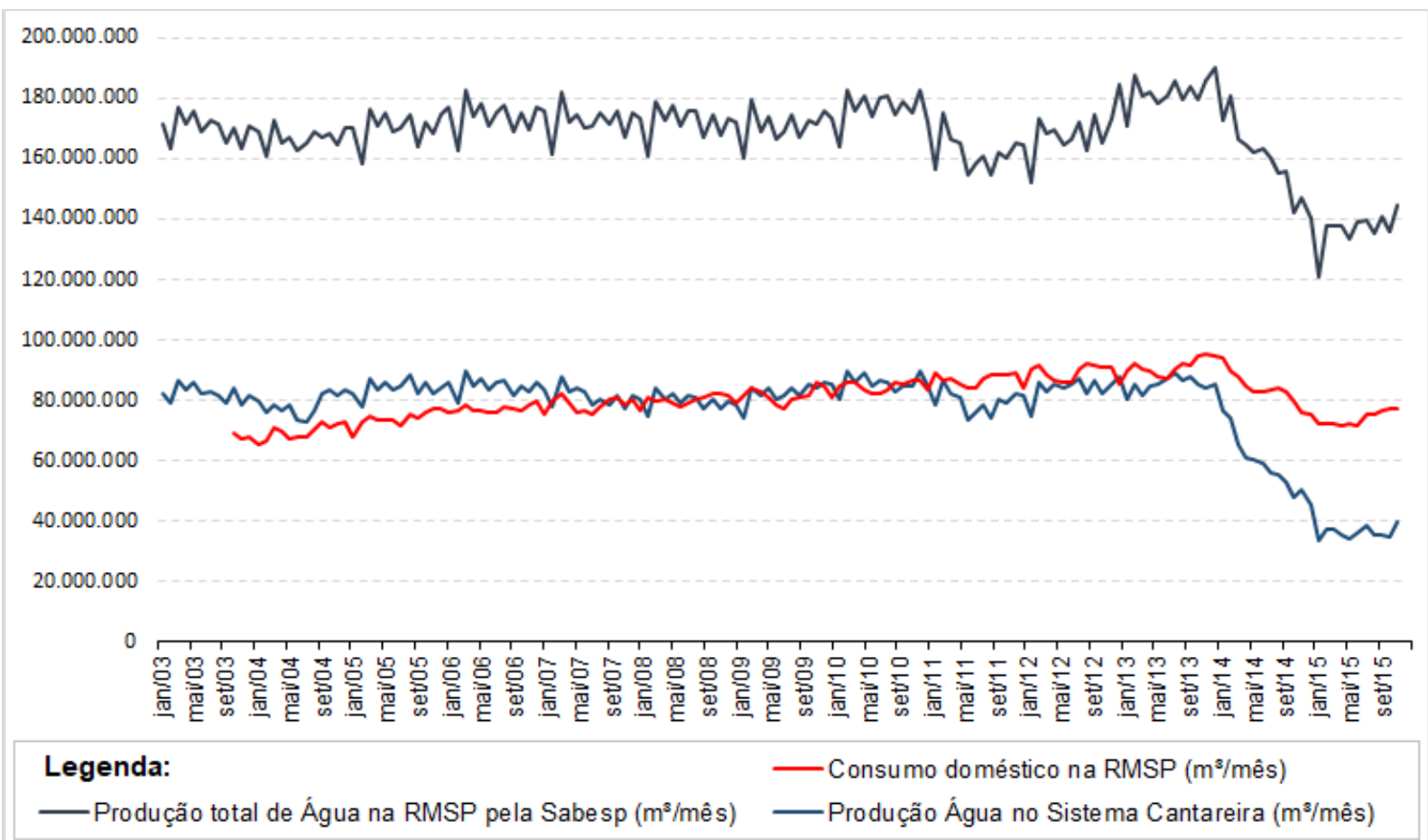

Figura 5 - Consumo mensal de água e produção hídrica na RMSP e no Sistema Cantareira.

Fonte: SABESP (2018).

Em uma análise integrada das figuras apresentadas nesse artigo, nota-se que a crise hídrica foi originada por uma seca meteorológica ocorrida na região e intensificada por chuvas mais reduzidas na porção setentrional da área de estudo, já na bacia hidrográfica do PCJ onde se insere os limites do Sistema Cantareira. No entanto, a despeito das chuvas já mostrarem-se reduzidas desde o ano de 2013, a produção hídrica do sistema e de toda a RMSP permaneceram elevados até janeiro de 2014, mês em que se registrou o maior consumo de água em toda a série histórica da metrópole. Desse modo, a partir de fevereiro de 2014, o reconhecimento tardio de uma situação de 'crise' levou a uma redução gradativa na produção hídrica, com destaque para o Sistema Cantareira, e uma diminuição do consumo de água, redução esta que se encontra associado a diversos impactos que foram registrados e noticiados na metrópole paulista.

Dessa maneira, a crise hídrica motivou impactos na região principalmente associados à falta d'água, e o volume do Sistema Cantareira passou a ser destacado quase diariamente nos principais jornais da metrópole, tendo em vista a possibilidade real de esgotamento desse sistema, que provocaria eventualmente um 
racionamento de água de grandes proporções. Em 2003, na última grande seca registrada na área de estudo antes desse evento, o nível do Cantareira e a reserva técnica do sistema (volume morto) era um assunto amplamente debatido, mesmo num hiato de mais de dez anos. Por exemplo, no dia 27 de novembro de 2003, o jornal O Estado de São Paulo (ESTADÃO, 2018) reportava: "Cantareira: nível cai e chega a $2 \%$ ", chegando inclusive a níveis inferiores nos dias seguintes. A respeito disso, o colunista Fernando Reinach (2014, p. 95) analisa essa situação em uma publicação no Estadão em 10 de maio de 2014, relatando que:

"O que poucos lembram é que esta é a segunda vez que vamos beber água do volume morto, a primeira foi no final de 2003, na última grande seca. Naquele verão, o nível da represa chegou a $0 \%$ e até atingiu valores negativos (...) Mas, em agosto de 2004, algo estranho acontece nas estatísticas. De repente, o índice pula de próximo a zero para $22 \%$, como se durante uma noite a represa tivesse enchido mais de $20 \%$. A explicação oficial veio em seguida. Com a renovação da concessão da exploração do Sistema Cantareira, com uma canetada, o limite que define o volume morto passou da cota de 829 metros para a cota de 820,80 metros. Com essa canetada, 209 bilhões de litros de água foram ressuscitados e transferidos do volume morto para o volume útil. $E$ a cota que define o início do volume morto foi reduzida em 8 metros. Portanto, no auge da crise, sem gastar um centavo, a Sabesp passou a dispor de mais água para vender aos consumidores de São Paulo. E, com uma reserva maior, a mesma caneta que ressuscitou a água, aumentou a permissão de retirada de água do Sistema Cantareira" (REINACH, 2014, p. 95).

No entanto, as intensas e volumosas precipitações observadas entre 2009 e 2011 podem ter contribuído para que os governantes e órgãos gestores não levassem em consideração ou não priorizassem o planejamento da água na metrópole, afinal havia uma situação de 'bonança hídrica'. A respeito disso, por exemplo, pode-se citar a entrevista divulgada no dia 20 de fevereiro de 2014, com o então presidente do Conselho Mundial da Água, Benedito Braga (2014, p. 22):

"A crise da falta d'água é esperada no Estado de São Paulo há mais de uma década e vai além da seca extrema deste verão. Só que sempre que começa a chover, todo mundo esquece o risco e volta a gastar água de modo inconsequente. (...) Há uns quatro anos ou mais já venho dizendo isso. Em 2004 tivemos uma situação semelhante, o reservatório estava com $20 \%$, mas começou a chover após a concessão da outorga e todo mundo se esqueceu do problema. Mas, quando se faz uma análise de longo prazo, vemos que nos últimos 15 anos o sistema vem recebendo menos contribuição de água da bacia do que a média histórica. Ele não consegue se recuperar. Pode ser que estejamos num ciclo de vazões baias naquela bacia. Esses períodos de variabilidade climática acontecem e temos de estar preparados para isso. É hora de a classe política entender que água é importante. Mas depois que a crise passa, todo mundo esquece" (BRAGA, 2014, p. 22).

Estudos Geográficos, Rio Claro, 17(1): 43-54, jan./jun. $2019 \quad$ (ISSN 1678-698X) 


\section{CONSIDERAÇÕES FINAIS}

Os resultados obtidos e as discussões em questão tornaram possível verificar os períodos (cronológicos) de maior concentração pluviométrica sazonal e interanual nos diferentes setores latitudinais da RMSP e do Sistema Cantareira. Do mesmo modo, notou-se uma situação bastante complicada e complexa enfrentada pelo principal sistema de abastecimento de água da metrópole durante a crise hídrica, que foi motivada por uma seca meteorológica na região e, muito provavelmente, intensificada pela falta de planejamento voltado à gestão de recursos e riscos hídricos na RMSP, com destaque para o abastecimento urbano e o fenômeno das secas, demandando novos paradigmas mais modernos de gestão dos recursos hídricos (HESPANHOL, 2008) e de análise da dinâmica do ritmo climático e de suas variabilidades (MONTEIRO, 2015).

\section{REFERÊNCIAS}

ANA. Agência Nacional de Águas. Disponível em: <http://www.ana.gov.br/>. Acesso em: 3 set. 2018.

BRAGA, B. Deveríamos economizar água desde 2004. O Estado de São Paulo, São Paulo, Metrópole, p. 22, 20 fev. 2014.

COELHO, C. A. S.; CARDOSO, D. H. F.; FIRPO, M. A. F. Precipitation diagnostics of an exceptionally dry event in São Paulo, Brazil. Theoretical and Applied Climatology, v. 125, p. 769-784, 2016.

COPASA. Companhia de Saneamento de Minas Gerais. Disponível em: <http://www.copasa.com.br/wps/portal/internet/>. Acesso em: 5 nov. 2018.

CUSTÓDIO, V. A crise hídrica na região metropolitana de São Paulo (2014-2015). GEOUSP: Espaço e Tempo, v. 19, n. 3, pp. 445-463, 2015.

DAEE. Departamento de Águas e Energia Elétrica do Estado de São Paulo. Disponível em: <http:// www.daee.sp.gov.br/>. Acesso em: 6 set. 2018.

ESTADÃO. Acervo Estadão - Jornal O Estado de S. Paulo. Disponível em: <http://acervo.estadao.com.br/>. Acesso em: 4 jun. 2018.

FUSP. Plano da Bacia Hidrográfica do Alto Tietê: Relatório Final. São Paulo: FUSP, 2009.

HESPANHOL, I. Um novo paradigma para a gestão de recursos hídricos. Estudos Avançados, v. 22, n. 63, pp. 131-158, 2008.

JACOBI, P. R.; CIBIM, J. ; LEÃO, R. S. Crise hídrica na Macrometrópole Paulista e respostas da sociedade civil. Estudos Avançados, v. 29, n. 84, pp. 27-42, 2015. 
LIMA, K. C.; SATYAMURTY, P.; FERNÁNDEZ, J. P. R. Large-scale atmospheric conditions associated with heavy rainfall episodes in southeast brazil. Theoretical and Applied Climatology, v. 101, pp. 121-135, 2010.

MONTEIRO, C. A. F. (Org.). A construção da Climatologia Geográfica no Brasil. 1ํㅡㄹ Edição. Campinas, SP: Editora Alínea, 2015.

PORTO, R. L.; PORTO, M. F. A.; PALERMO, M. A ressurreição do volume morto do Sistema Cantareira na Quaresma. Revista DAE, v. 197, pp. 18-25, 2014.

REINACH, F. Ressuscitando morto com caneta. O Estado de São Paulo, São Paulo, Metrópole, p. 95, 10 mai. 2014.

ROSS, J. L. S. Problemas ambientais das regiões metropolitanas: as águas na grande São Paulo. Sociedade e Território, v. 20, n. 2, pp. 335-346, 2008.

SABESP. Companhia de Saneamento Básico do Estado de São Paulo. Disponível em: < http://site.sabesp.com.br/>. Acesso em: 6 mai. 2018.

SANT'ANNA NETO, J. L. As Chuvas no estado de São Paulo: contribuição ao estudo da variabilidade e tendência da pluviosidade na perspectiva da análise geográfica. 1995. Tese de Doutorado em Geografia apresentada à Universidade de São Paulo (USP/FFLCH - SP, Brasil).

SCHNEIDER, H.; SILVA, C. A. O uso do modelo box plot na identificação de anospadrão secos, chuvosos e habituais na microrregião de Dourados, Mato Grosso do Sul. Revista do Departamento de Geografia, v. 27, pp. 131-146, 2014.

SIGRH. Sistema Integrado de Gerenciamento de Recursos Hídricos do Estado de São Paulo. Disponível em: <http://www.sigrh.sp.gov.br/>. Acesso em: 12 set. 2018.

SILVESTRE, M. R.; SANT'ANNA NETO, J. L.; FLORES, E. F. Critérios estatísticos para definir anos padrão: uma contribuição à climatologia geográfica. Revista Formação, v. 2, n. 20, pp. 23-53, 2013.

WHATELY, M.; CUNHA, P. Cantareira 2006: um olhar sobre o maior manancial de água da Região Metropolitana de São Paulo. São Paulo: ISA, 2007.

WHATELY, M.; DINIZ, L. T. Água e esgoto na grande São Paulo: situação atual, nova lei de saneamento e programas governamentais. São Paulo: Instituto Socioambiental, 2009. 
A ‘crise hídrica'...

Agradecimentos

O primeiro autor agradece ao Conselho Nacional de Desenvolvimento Científico e Tecnológico (CNPq) pela concessão da bolsa de pós-graduação em nível de doutorado no período de outubro de 2017 a dezembro de 2018. Da mesma forma, entre os meses de abril de 2015 a setembro de 2017, o presente trabalho foi realizado com apoio da Coordenação de Aperfeiçoamento de Pessoal de Nível Superior - Brasil (CAPES) - Código de Financiamento 001.

Estudos Geográficos, Rio Claro, 17(1): 43-54, jan./jun. $2019 \quad$ (ISSN 1678-698X) 